\title{
SARA Malvar: UnA PROPUESTA DE POEMA EN PROSA*
}

\section{Patricio Lizama A**}

\section{Resumen}

En este trabajo analizamos,de manera breve,la comprensión que tiene Sara Malvar de la poesía moderna y de las problemáticas artístico-culturales del creador en la modernidad periférica. Luego, en el núcleo del trabajo, estudiamos su texto llamado "Tennis" el cual es definido como poema en prosa y leído en relación con la arquitectura moderna y con una concepción ocultista del universo.

Palabras clave: Poesía moderna, poema en prosa, arquitectura moderna, ocultismo.

\section{SARA MALVAR: A PROPOSED PROSE POEM}

\begin{abstract}
In this work we analyze, briefly, Sara Malvar's understanding of modern poetry and the creator artistic and cultural issues in peripheral modernity. Then, in the core of the work we study the text called "Tennis," which is defined as a prose poem and read in relationship to modern architecture and with an occultist conception of the universe.
\end{abstract}

Keywords: Modern Poetry, prose poem, modern architecture, occultism.

* El presente trabajo es parte del proyecto Fondecyt Regular $\mathrm{N}^{\circ} \mathbf{1 1 5 0 5 3 5}$ "Poema en prosa y modernidad en Chile: 1888-1945", del cual soy investigador responsable. Una versión más completa acerca del aporte de Sara Malvar será desarrollada en un libro que preparo.

** Chileno. PhD. Profesor Titular de la Pontificia Universidad Católica de Chile, Santiago, Chile. plizama@puc.cl 
Sara Malvar es poco conocida en Chile. Artista plástica formada en la academia, se casa con el pintor chileno José Backhaus y viaja a España en 1917. Viven en Ávila, luego en Madrid, capital donde exponen en julio de 1920. Al año siguiente se trasladan a París, conocen a Eugenia Huici, y a través de ella, entre otros, a Pablo Picasso, Le Corbusier, Robert y Sonia Delaunay. Al mismo tiempo visitan a Wanda Morla, Vicente Huidobro, Jean Emar y a varios pintores chilenos quienes también residen en la capital francesa. En octubre de 1922, Sara vive una profunda crisis originada por la repentina muerte de su esposo en París , y a fines del año siguiente regresa a Chile.

La acabada comprensión del arte moderno que Malvar articula en París, le permite participar en 1924 y 1925 en el proyecto de las "Notas de Arte"dirigido por Jean Emar en La Nación, página en la que ella escribe con gran lucidez acerca de Arthur Rimbaud, Guillaume Apollinaire, Vicente Huidobro, Amadeo Modigliani, Henri Rousseau, Le Corbusier, Erik Satie, y traduce un fragmento del manifiesto del surrealismo. Su aporte también lo encontramos en sus adelantadas propuestas acerca de los problemáticas artísticas y culturales que enfrenta el creador de la vanguardia hispanoamericana.

En 1924, ella los llama a abandonar el color local y a acoger "la tradición humana, que no sabe de razas ni de épocas" (Emar 186), planteamientos presentes en algunos manifiestos latinoamericanos y que una década más tarde desarrollarán Alfonso Reyes y Borges. Asimismo, los invita a replantearse la búsqueda de la originalidad al concebir la creación como un trabajo intertextual, pues sostiene que "la historia de la pintura no es sino una cadena ininterrumpida de influencias" surgidas del "choque, la fusión de corrientes diversas o contrarias" y concluye: "los grandes artistas 'han imitado, han copiado, y[...]han sido siempre ellos mismos'" (Emar186). Por último, anima a los artistas chilenos a viajar a Europa porque percibe la poca autonomía, la carencia de estímulos y el inevitable tedio en el campo plástico nacional. Afirma que "el ambiente y las condiciones actuales, [son] más propicias al parecer para anquilosar cualquier organismo que para ayudar a cambiar un estado de cosas" (Emar186). 


\section{Sara Malvar y la poesía moderna}

En las Notas de Arte, Emar escribe sobre la "razón de ser" de la pintura moderna y Malvar hace lo mismo respecto a la poesía moderna; para explicitar la génesis y evolución de la nueva lírica, utiliza las categorías de Le Corbusier referidas a la arquitectura y distingue a los "constructores" de los "precursores". Señala que Rimbaud es un precursor, ya que se aleja de la representación mimética y la escritura descriptiva, explora lo desconocido, revela lo indecible y expresa el inconsciente a través de una continua búsqueda experimental. Agrega que en la base de su obra existe una percepción visionaria capaz de aprehender "todas las relaciones y el infinito continuo" y plasmar "un mundo alucinado de imágenes y analogías donde todo se corresponde y cambia" (Emar112).

Entre los constructores, señala a Apollinaire y,a partir del impacto de la pintura en su poesía, destaca sus versos fragmentarios y discontinuos, sin puntuación, y la variada tipografía que permite construir relaciones poéticas originales y constelaciones de imágenes sugerentes en el espacio de la página. Huidobro es el otro constructor porque, en la imagen creacionista, aproxima realidades lejanas, establece relaciones secretas e imprevistas y genera una belleza "subterránea", planteos que dialogan con las propuestas de Reverdy y más tarde con la visión de la imagen que tienen los surrealistas (Emar174).

Junto con mostrar la "razón de ser" de la poesía contemporánea, Malvar define el texto poético y lo hace con una mirada transversal, ya que los elementos y procesos que ella distingue-pensamiento nuevo, trabajo de composición, imágenes condensadas, síntesis, participación del lector-son también esenciales en otras manifestaciones artísticas como la pintura, la arquitectura y el cine. Con gran lucidez para la época, ella señala en junio de 1924, rasgos esenciales de la lírica emergente:

Todo poema moderno en que los pensamientos se esquematizan hasta el último límite, en que la descripción se reduce a uno o dos términos justos, precisos, en que las imágenes son como concentraciones de pensamientos, exige del lector un trabajo complementario de reconstrucción, de sensibilidad casi paralelos al autor. (Emar 116) 


\section{Sara Malvar y el poema en prosa}

Los planteamientos anteriores y esta definición de la poesía de Malvar, los encontramos realizados en un texto escrito por ella llamado "Tennis" que aparece en las "Notas de Arte" de octubre de 1924 y que evidencia su fascinación por la vida moderna. Leamos:

En el campo geométrico del court, los jugadores, cuatro puntos blancos. Movientes formas en equilibrio.

-He visto jugar a los Torralba, a los Robson, Boyd y Zumelzú -juego neto, preciso, lleno de juventud, nervioso y controlado a un tiempo. A veces, gestos, movimientos de pura belleza.

Parecían obedecer al llamado imperioso de las fuerzas multiplicadas, del ritmo que acelera y renueva la vida (Emar140).

El texto,construido con una voluntad consciente de organizar el discurso en forma poética, lo entendemos como un poema en prosa, "género poético breve de ideación moderna" modelado por Aloysius Bertrand y reformulado por Baudelaire al intentar un nuevo modo de percibir y representar la vida en la modernidad (Aullón de Haro 22). Lejos de la intención moralizante, didáctica u oratoria, el poema en prosa está construido con una estética de lo fragmentario y discontinuo que transgrede la oposición entre verso y prosa y el proceso mismo de la escritura.

Su articulación fundada en la intensidad lírica, en "la brevedad y la concentración temática" (Fernández 32), carece de una forma fija y de los mecanismos tradicionales de la poeticidad como el verso, el ritmo y la rima -fuerzas destructoras- pero contiene un juego de repeticiones, antítesis, paradojas, estructuras paralelísticas y simétricas que le otorga estabilidad -fuerzas constructoras- y logra encerrar al lector en sus límites, pues su objetivo "es el de cercar en todo lo posible el acto de mirar" (Tenreiro 68).

Los contrastes, contradicciones y desgarramientos establecen una dualidad en la estructura temática y en la composición, y permiten entender al poema en prosa como un texto en tensión de base oximorónica que se define como una "asociación de opósitos" porque subraya el encuentro de los contrarios. La confrontación e integración de contrarios 
da origen a un universo altamente organizado que se funda en la analogía universal, el trabajo de las correspondencias y el principio de semejanza.

\section{"Tennis": síntesis, fragmento y discontinuidad}

El espacio -"campo geométrico"-, los jugadores - "cuatro puntos blancos", "movientes formas"-, el juego -nervioso, controlado- y las acciones -gestos, movimientos-, son caracterizados con una estética del sugerimiento basada en una cuidadosa síntesis y una gran economía de medios. La brevedad, la condensación y la sugerencia se explican porque la artista chilena no desea narrar una historia ni hacer una descripción extensa; al contrario, y de acuerdo a su concepto del poema moderno, ella usa "uno o dos términos justos, precisos" (Emar 116) porque hace la "guerra a la anécdota" como diría Huidobro, proceso que también se manifiesta en la plástica -"guerra a la literatura en la pintura"-, en la arquitectura -despojo del adorno y del ornamento- y en la literatura como es el caso del microrrelato.

Asimismo, Malvar utiliza una estética de lo fragmentario y lo discontinuo, la cual define la experiencia esencial del sujeto en la modernidad y tiene su raíz en lo sostenido por Baudelaire. La escritura elíptica, semejante a la del cine, reduce la longitud de los segmentos, condensa la información y la expresividad en los sustantivos, no en los verbos, y elimina los nexos y la coordinación explícita de las oraciones. Ella,con párrafos muy breves,rompe el desarrollo lineal, pues construye una cadencia entrecortada, una secuencia discontinuada de fragmentos a base de cortas y delimitadas repeticiones cuya unión surge del encuentro de imágenes yuxtapuestas encadenadas en forma secreta. Esta relación de eslabones convergentes obliga al lector a desarrollar una capacidad asociativa y revela un ritmo de vida ligado a la agilidad y a la instantaneidad. Malvar concibe un texto que no crece hacia afuera, sino hacia dentro (Anson 29).

\section{"Tennis": objeto moderno, asociación de contrarios y estructura simétrica}

Malvar, alejada del color local y de la naturaleza como fuente del arte, es seducida por un objeto moderno, el juego de tenis, percepción que la transforma en una máquina de ver, en un "espectáculo de orden" que 
destruye la visión ilusionista y anecdótica del objeto. Ella "mira desde arriba" con una percepción que borra las distancias normales y aplasta la tierra en una superficie de modo que ve la cancha de tenis como una planta arquitectónica tal como se vería "a vuelo de pájaro". ${ }^{2}$

El juego, universo ordenado, es una "confrontación de contrarios". El tenis enfrenta a pares de participantes, su desarrollo alterna reposo y movimiento, y supone obligaciones e invenciones, disciplina e improvisación, norma y libertad. Los desplazamientos que exigen gran rapidez y precisión son cortos y largos, hacia adelante y hacia atrás, a derecha e izquierda y ocurren dentro y fuera de los límites de la cancha. Los "gestos y movimientos de pura belleza" configuran una epifanía de formas que surge de modo sorprendente, que aparece y desaparece, y genera en el espectador una fascinación que lo captura y le provoca una intensa concentración. ${ }^{3}$ El juego es "una conjunción de opuestos" según Huizinga, al igual que el poema en prosa.

El tenis tiene su origen en el mundo francés, luego se extiende al anglosajón-espacio donde lo renombran Tennis y establecen las reglas-y después se universaliza (Cavalla 46). En el poema, los jugadores enfrentados son de dos países, los hermanos Luis y Domingo Torralba son de Chile y Guillermo Robson, Ronald Boyd y Adolfo Zumelzú son de Argentina. Todos son latinoamericanos, pero algunos tienen orígenes hispanos y otros anglosajones, dualidad que también se advierte en el texto entre el título "Tennis", término en inglés, y los párrafos escritos en español.Esta tensión se extiende a una polaridad mayor entre el lado de allá, la modernidad central que inventa y codifica el juego, y el lado de acá, modernidad periférica, que lo apropia y le introduce variantes. ${ }^{4} \mathrm{El}$ tenis, como el poema en prosa, es"una asociación de opósitos" (Moga 38).

El terreno de juego para Malvar es un "campo geométrico" que ella sustrae de su realidad de uso, lo convierte en un "objeto encontrado" al margen del arte oficial y de la industria al que le otorga valor plástico,y

2 Nuestro concepto del objeto, señala Le Corbusier, se basa en su conocimiento total: sentidos, materia, volúmenes, perfil, propiedades. Ver Juan Carlos Sancho, El sentido...

3 Ver Hans Ulrich Gumbrecht. Elogio de la belleza atlética. Buenos Aires: Katz, 2006.

4 William Cox, naturalista y explorador de origen británico, es el primero en instalar una cancha de tenis en el país, acontecimiento que ocurre en Valparaíso en 1882. La cancha no es de pasto pues la hace con "la tierra arcillosa mezclada con maicillo". Más tarde aparecerán en el país canchas de ripio, líneas demarcadas por tablones sujetos con zunchos", canchas de baldosas. Ver Mario Cavalla, Historia... 
lo entiende desde una perspectiva arquitectónica presidida por la geometría y el pensamiento purista de Ozenfant y Jeanneret. La cancha es una composición ortogonal de rectángulos cuadrados sin diagonales ni curvas, construida a base de rectas y ángulos rectos y donde se advierte una simetría rectangular perfecta respecto a la red.

Las líneas verticales y horizontales existentes a los dos lados de la cancha conforman una trama de paralelas y perpendiculares que se refuerza con la igualdad de los pares de rectángulos y cuadrados a cada lado del court. El tejido de paralelismos que caracteriza a la cancha configura un equilibrio estático y una estructura simétrica que posee ritmo y cadencia, porque la semejanza es factor relevante del ritmo. La simetría se convierte en "aguda percepción del orden" y no en "operación mimética" (Sancho 74). El court nace del cálculo, la síntesis y la claridad, y revela las virtudes de la belleza valorada por el purismo: rigor, proporción y geometría.

\section{“Tennis": juego, equilibrio, simetría}

El juego es una totalidad cerrada que crea su propio mundo ajeno al curso habitual de la vida, pues propone un orden, un espacio y un tiempo otros donde se despliegan acciones ligadas a la alternancia, la tensión antitética, la armonía y el ritmo. Estas acciones dan lugar a movimientos y a una infinita variedad de disposiciones y principios.

Malvar contempla a los jugadores de tenis como "movientes formas en equilibrio", cuerpos en relación que estallan hacia todas las direcciones y vínculo de contrarios que por medio de giros y traslaciones introducen una dispersión en el espacio. El movimiento de los "cuatro puntos blancos" plasma una continua metamorfosis y una multiplicidad que originan una perturbación de la simetría y revelan un nuevo ritmo, una forma singular de sucederse y alternar de los desplazamientos: crean figuras de gran belleza.Esta armonía, como la del universo donde existen realidades que parecen no conciliarse, "no es ausencia de contrastes, sino equilibrio" porque los contrarios no se anulan sino que viven en una tensión continua (Eco 72).

El equilibrio ahora es dinámico, supone otro ritmo y tiene su correlato en la concepción de simetría de Le Corbusier, quien afirma que la 
correspondencia exacta en forma, tamaño y posición de las partes de un todo, es una "falsa acepción de igualdad mantenida por un academicismo siempre vivaz". Él propone, en cambio, "situar el término [simetría] en su plano original que es el del equilibrio de los contrarios" pues "expresa una relación ilimitada, tensa, entre dos términos" (Sancho 109).

El juego del tenis, cancha y jugadores actualiza equilibrios, repetición, simetrías, modulacióny ritmos enfrentados que se armonizan, dualismo y confrontación, movimiento, equilibrio de contrarios, encuentro de este en la confrontación, rasgos que están en la base del poema en prosa.

\section{"Tennis: ritmo, universo y poeta}

El poema en prosa se organiza desde el interior y encuentra "allí su propio centro de gravedad, su propio foco de energía, su propia e íntima profundidad de comprensión" (Fernández 32$)^{5}$. La cancha de tenis es para Malvar una ordenación visual del mundo entendida en su belleza y perfección formal, objeto estético. A la vez, es un centro de convergencia e irradiación de fuerzas universales, objeto mágico. La cancha es un espacio ilimitado, pero finito (Cirlot 68).

El movimiento en equilibrio de los tenistas es visto por Malvar en correspondencia con las fuerzas y el ritmo de las leyes de la naturaleza, lo que revela una concepción rítmica y ocultista del universo. Esta nueva "asociación de opósitos" vincula el mundo visible y terrenal con el invisible, celestial, a través de sutiles y misteriosos lazos porque todo rima, se llama y se responde. A la vez,la conexión de estos dos mundos devela la presencia del principio esotérico, "lo que está abajo es como lo que está arriba, y lo que está arriba es como lo que está abajo". ${ }^{6}$

A partir de estos planteamientos, las figuras y formas construidas por los jugadores son un microcosmos en interacción constante con los movimientos y ritmos del macrocosmos. Las correspondencias se nutren de este contacto y, por ello, si Darío ve en la danza de Isadora Duncan la concentración y encarnación del ritmo cósmico, Malvar lo ve en el

5 Fernández cita a Mary Ann Caws, "The Self Defining Prose Poem: on its edge". The prose poem in France. New York: Columbia University Press, 1983. 180.

6 http://eruizf.com/martinismo/kibalion/el_kibalion_05.html 
movimiento de los jugadores de tenis, deporte moderno que también es otra danza con sus propios ritmos.

Por último, si el universo "está compuesto por contrarios que se unen y se separan conforme a cierto ritmo secreto" (Paz Busqueda 43), si de las discordias surge una armonía oculta ligada a tensiones opuestas que dejan de ser percibidas en forma contradictoria,el mundo parece un complicado tejido de acontecimientos en el que toda suerte de conexiones se alternan, se superponen o se combinan y, de este modo, determinan la textura del conjunto.

Malvar, en este poema en prosa, advierte simetrías entre dos mundos, correspondencias que se mantienen ocultas y están superpuestas no en transparencia sino en opacidad. Ella intuye una totalidad, vislumbra un modo de conocimiento y cumple la función esencial del poeta. En palabras de Baudelaire, ¿qué es un poeta sino un traductor, descifrador?" (Paz Hijos 108); en palabras de Poe, "el mundo material está lleno de analogías rigurosas con el mundo inmaterial" (Azcuy 27). Malvar descifra y revela una analogía.El conocimiento poético -la imaginación, la facultad productora de imágenes en cuyo seno los contrarios se reconcilian- nos deja vislumbrar la analogía cósmica (Paz Las peras 149).

\section{Palabras finales}

Baudelaire, con ecos platónicos, señala: "El mortal instinto de lo bello [es] el que nos hace considerar la tierra y sus espectáculos como una correspondencia del cielo" (Rella 17). La artista chilena ve el tenis como una analogía del universo y sus leyes, capacidad que surge de una clarividencia que la define como vidente.Ella posee una segunda vista, una imaginación más aguda y un sentido más allá del tiempo y el espacio, conciencia abierta y visión superior capaz de descubrir correspondencias y revelar analogías del mundo habitado por el hombre.

A través de un proceso de abstracción, Malvar realiza un "viaje inmóvil" que territorializa y desterritorializa. La artista, con ilimitada expansión de la mirada y del rango de perspectivas con que mira, es un "caleidoscopio dotado de conciencia" con sensibilidad hacia "lo transitorio, lo fugitivo, lo contingente", pensamiento que define la experiencia de la modernidad y que está en la base del poema en prosa. Ella captura "imágenes momentáneas", "fragmentos fortuitos de 
realidad" en los que busca las sugerencias de eternidad en el presente que pasa, busca la dimensión intensiva del instante pues se trata de "imprimirle a la contingencia una infinita reverberancia".(Hopenhayn 133)

Los movimientos de los cuerpos en relación se pueden entender como desplazamientos eurítmicos que expresan lo suprasensible. Para Steiner, la euritmia es un arte que, a través del lenguaje plástico del movimiento humano, busca expresar el ser eterno y el aspecto divino-espiritual contenido en el hombre. Lo anímico espiritual se manifiesta en lo físico corporal y la euritmia puede poner "al ser humano en consonancia con el universo" (65). Asimismo, se pueden entender como un yo místico, alma del mundo que se une a las energías armoniosas, identificación mística que procede de "la intuición que forma la base de los ocultismos de todas las razas: el de la identidad del hombre integral -con el desarrollo de todas sus facultades humanas y divinas- y el universo, con todas sus fuerzas en acción" (Cirlot 68).

Malvar, ya en los años veinte, se abre el patrimonio universal y se siente con pleno derecho a usar y transformar este legado. Ella acude a la tradición con una mirada selectiva y reelabora un género, el poema en prosa. Si Darío inaugura la serie genérica del poema en prosa en Hispanoamérica con el modernismo en Azul, la obra de Pedro Prado agrega el énfasis de lo propio en el mundonovismo y Malvar agrega una nueva propuesta que nace de su vínculo con la vanguardia. 


\section{Referencias Bibliográficas}

Anson. El istmo de las luces. Madrid: Cátedra, 1994.

Aullón de Haro, Pedro. "Teoría del poema en prosa". Quimera 262(Octubre 2005): 22-25.

Azcuy, Sergio. El ocultismo y la creación poética. Caracas, Monte Avila Editores, 1983.

Cavalla, Mario. Historia del tenis en Chile. 1882-2006. Santiago: Ocho Libros editores, 2006.

Cirlot, Eduardo. El mundo del objeto a la luz del surrealismo. Barcelona: Anthropos, 1986.

Eco, Umberto. Historia de la belleza. Barcelona:Lumen, 2004.

Emar, Jean. Notas de Arte. (Jean Emar en La Nación. 1923-1927). Estudio y recopilación Patricio Lizama. Santiago: Dibam-Ril, 2003.

Fernández, Jesse. El Poema en prosa en Hispanoamérica. Madrid: Hiperión, 1994.

Hopenhayn, Martín. Después del nihilismo. De Nietzsche a Foucault.

Santiago: Andrés Bello, 1997.

Moga, Eduardo. "La poesía en prosa de Manuel Álvarez Ortega. Sintaxis del alma". Quimera 262 (octubre 2005): 36-39.

Paz, Octavio. Las peras del olmo. Barcelona: Seix Barral, 1971.

--- Los hijos del limo. 3` edición. Barcelona: Seix Barral, 1990.

--- La búsqueda del comienzo. Escritos sobre el surrealismo. 3 ed. Madrid: Editorial Fundamentos, 1983.

Rella, Franco. La búsqueda del presente. Miradas sobre la modernidad. Barcelona: Ediciones UPC, 1995.

Sancho, Juan Carlos. El sentido cubista de Le Corbusier. Madrid: Editorial Munilla-Lería: 2000.

Steiner. Euritmia. Lenguaje visible del alma. Madrid: Ed. Rudolf Steiner, 1992. 
Tenreiro, Salvador. El poema plural. Notas sobre la poesía contemporánea. Caracas: Ediciones La Casa de Bello, 1989. 